\title{
Aspiration Squeeze: The Struggle of Children to Positively Selected Immigrants
}

\author{
Per Engzell \\ Nuffield College, University of Oxford \\ Swedish Institute for Social Research (SOFI), Stockholm University
}

November 2018

An edited version of this manuscript is to appear in Sociology of Education

\begin{abstract}
Why is it that children of immigrants often outdo their ethnic majority peers in educational aspirations yet struggle to keep pace with their achievements? This article advances the explanation that many immigrant communities, while positively selected on education, still have moderate absolute levels of schooling. Therefore, parents' education may imbue children with high expectations but not always the means to fulfill them. Swedish data on children of immigrants from over 100 countries of origin support this view: net of parents' absolute years of schooling, a high rank in the sending country benefits children's aspirations, attitudes, and educational choices, but not their test scores or school grades. The upshot is an "aspiration squeeze" where, to emulate their parents' relative place in the education distribution, children are left struggling against the momentous tide of educational expansion.
\end{abstract}

\section{Acknowledgements}

Earlier versions of this paper were presented at the Swedish Institute for Social Research, 2014; the 7th Annual PhD Conference in Economic Demography, Lund, 2014; the Annual Meeting of the Swedish Network for Research on Social Policy and Welfare, Stockholm, 2014; the 19th Annual Aage Sørensen Memorial Conference, Princeton, 2015; and the Population Association of America (PAA) Annual Meeting, San Diego, May 2015. I thank the audiences and discussants at these occasions, three anonymous referees, and the editor for detailed and helpful comments that greatly improved the paper.

\section{Funding}

The current study was funded by grants from the Swedish Research Council for Health, Working Life, and Welfare (FORTE) (grant no. 2012-1741 and 2016-07099) and the Swedish Research Council (grant no. 2012-5598). The CILS4EU project was funded by New Opportunities for Research Funding Agency Co-operation in Europe (NORFACE). 


\section{Introduction}

The successful integration of foreign-background children presents one of the foremost challenges to schooling systems today (Heath, Rothon and Kilpi 2008; Alba, Sloan, and Sperling 2011). In the contemporary United States, over a fifth of children have at least one foreign-born parent, a proportion that is similar in Sweden and many other wealthy countries (Lessard-Phillips, Fleischmann, and van Elsas 2014). Often these families occupy precarious positions at the lower rungs of the status ladder. Meanwhile, a steadily aging population makes host countries reliant on immigration for their social and economic viability (Alba et al. 2011). It is therefore no surprise that integration generates considerable interest in sociology and beyond (Alba and Nee 2003; Heath and Cheung 2007).

Partly due to their families' economic disadvantage, but also difficulties unique to the immigrant experience - language deficits, acculturation, or discrimination - children of immigrants may struggle in school (Kao and Thompson 2003; Heath et al. 2008). Despite this, the most pessimistic scenarios appear unfounded. On the one hand, these children often earn lower test scores and grades, and are at greater risk of dropout (Heath and Brinbaum 2014). At the same time, they usually show higher aspirations than ethnic majority peers. This, in turn, leads to high rates of succession to academic and tertiary tracks, especially when prior achievement is taken into account (Heath and Brinbaum 2014).

Previous studies refer to this finding as "immigrant optimism" (Kao and Tienda 1995), "bold choices" (Jackson 2012), or "weak performance [but] strong determination" (Jonsson and Rudolphi 2011). The contrast is especially striking with social class differences within the majority population, where working class children are disadvantaged in both performance and choice (Jackson 2013). Some even proclaim the high minority aspirations a "paradox" (Kao and Tienda 1998; Salikutluk 2016; Feliciano and Lanuza 2017). While these accounts vary in which side of the asymmetry they view as in need of an explanation - aspirations or achievement - they converge on seeing it as an enduring sociological puzzle.

A promising recent line of research examines educational selectivity: where migrants ranked in the education distribution at origin (Feliciano 2005a; Ichou 2014; van de Werfhorst and Heath 2018). This research finds that many are positively selected, possibly explaining these families' resilience (Feliciano and Lanuza 2017). Yet, the precise nature of their advantage remains unknown. In particular, it is unclear why educational selectivity would benefit some aspects of children's education but not others. Most postulated transmission channels, including cognitive and non-cognitive skills, motivation, or academic habitus (Ichou 2014; Feliciano and Lanuza 2017), should arguably help achievement and attainment alike.

This study addresses these questions by taking an institutionally informed view on educational stratification. By treating a relative position in the sending and receiving country as comparable, previous work implicitly assumed that education systems differ only in the proportion who attain a given level and little else. But educational expansion is attended by profound social changes, including a turn toward increased selection on individual merit and 
away from inherited privilege (Breen and Jonsson 2007; Breen et al. 2009). Immigrants with high educational selectivity tend to come from countries at the beginning of this transition. Therefore a high relative education may imply strong parental expectations but only limited means to fulfill them outside the context where that education was attained.

To test this hypothesis I draw on data from Sweden, one of Europe's premier migration destinations. Three main considerations make this a particularly fertile testing ground for the theories proposed here. First, Swedish immigration is not only extensive but also exceedingly diverse, with more than 100 national origins represented in the data. Secondly, an egalitarian system with comprehensive and fully publicly funded schooling makes Sweden a limiting case, opportunities being more equal than almost anywhere. A third reason is data availability: high quality population registers linked to a recent survey - the Children of Immigrants Longitudinal Study in Four European Countries (CILS4EU) - offer a window on transmission mechanisms at a rare level of detail.

The results support the hypothesis: parents' educational rank at origin outdoes years of schooling as a predictor of adolescents' attitudes to education, occupational status aspirations, and transition to academic secondary tracks. In contrast, it appears to have limited relevance for test scores and school grades, where ethnic differences are largely accounted for by parents' years of schooling. As immigrants are often positively selected yet low educated in absolute terms, these findings are consistent with the pattern of low performance but high aspirations seen for many immigrant minorities.

Going further, I analyze just how estimates of second generation (dis)advantage change once this dual nature of parental education is taken into account. A detailed and reliable measure of parents' years of schooling all but eliminates the performance disadvantage of minority children. In contrast, the minority advantage in aspirations is only partly reduced with controls for parents' educational selectivity, leaving room for a complex understanding of "immigrant optimism". Future research should consider the conditional nature of the benefits that accrue to educational selectivity, and incorporate sending countries' stratification regimes into theory and analytical designs.

\section{Background and previous literature}

During the past half century, Western countries have seen dramatic changes in the scope and composition of immigration. Accompanying this is a heightened concern with the integration of migrants and their children. Successful integration would benefit not only migrants by reducing their marginalization, but also the economy at large, and is a key political objective (Alba et al. 2011). On the flip side, there is worry that a failure to integrate newly arrived minorities might create lasting discord or, at worst, entrenched conflict (Heath and Demireva 2014).

Following these developments, issues of migration and integration have moved to a center stage not just of policy and public debate, but also of social science. The last decade has seen 
considerable advances in efforts to compare the adaptation of migrants and their children in education systems and labor markets across countries of destination (Heath and Cheung 2007; Alba and Waters 2011; Alba and Holdaway 2013; Heath and Brinbaum 2014). These efforts have yielded important insights and recently sparked a first generation of dedicated projects aimed at collecting fully harmonized cross-country data (Crul, Schneider, and Lelie 2012; Kalter et al. 2013; Diehl et al. 2016).

For many, the decisive test of integration is how children of immigrants, not their parents, fare in the receiving country (Portes and Zhou 1993; Zhou 1997). Whereas several factors may hold back adult immigrants - such as limited knowledge of language and institutions, poor transferability of skills, or lack of social networks - these should, it is hoped, apply with less force to their children who experienced (most of) their upbringing in the new country. Given the importance of educational success in life, early indicators thereof are a critical source of information about future ethnic stratification (Kao and Thompson 2003; Heath et al. 2008; Alba et al. 2011).

\section{The mixed successes of ethnic minority youth}

Research on the education of foreign-background youth paints a mixed picture, depending on whether one considers performance outcomes such as test scores or school grades, or attainment outcomes such as educational decisions or final level of education. Separating these two dimensions has a long tradition in sociology and is illuminating as partly different mechanisms are likely to underlie each (Boudon 1974; Jackson 2013).

As for performance, some minority groups - often of Asian origin - rival or surpass majority children, and are sometimes held up as "model minorities" (Jackson, Jonsson, and Rudolphi 2012; Lee and Zhou 2015). However, many others find themselves at a disadvantage. Like majority children from poor homes, they achieve lower test scores and school grades on average (Schnepf 2007; Jackson et al. 2012; Heath and Brinbaum 2014). In the U.S., groups of particular concern include Hispanic minorities of Mexican, Dominican, or Puerto Rican descent (Hirschman 2001). In Sweden, disadvantaged minorities hail predominantly from Africa, the Middle East, and Latin America (Jonsson and Rudolphi 2011; Jackson et al. 2012).

That children of immigrant origin suffer a performance disadvantage is perhaps not unexpected, however objectionable. Even for children born and raised in the host country, parents continue to play a tremendous role and whatever impeded their integration may have a lingering influence (Heath and Cheung 2007). Limited language proficiency, lack of institutional knowledge, or lower socioeconomic resources curtail the support that immigrant parents can provide (Lutz 2007; Schnepf 2007; Casey and Dustmann 2008). Moreover, they may live in disadvantaged areas with access to poorer schools, facilities, and peer groups (Konczal and Haller 2008; Kroneberg 2008; Alba et al. 2011).

This pattern is reversed once we turn to educational choices. In contrast to white working class children, aspirations in these groups are high (Kao and Tienda 1998; Feliciano and 
Lanuza 2016). They are also more persistent and concrete than those of involuntary minorities, notably African Americans in the U.S. (Ainsworth-Darnell and Downey 1998; Raleigh and Kao 2010). Hence, a high proportion go on to some form of tertiary education, especially given prior achievement (Glick and White 2004; Keller and Tillman 2008; Heath and Brinbaum 2014).

In Sweden, Jackson et al. (2012) show that minority groups are overrepresented in academic secondary tracks despite some of them lagging in school grades with up to half a standard deviation (Jackson et al. 2012:166). A similar pattern reappears at entry to university, and is echoed by findings in, e.g., England, Germany, France, and the U.S. (Heath and Brinbaum 2014). Thus, unlike economically marginalized children in the majority who are doubly disadvantaged, immigrant minorities use opportunities for choice to compensate for poor prior performance.

A range of explanations have been proposed for these patterns (Sue and Okazaki 1990; Zhou and Bankston 1994; Kao and Tienda 1995, 1998; Zhou and Kim 2006). Among the most common is that immigrants are a select group (Lee 1966). Having chosen to migrate, they possess a "drive" or desire to integrate. But given costs of migration, they may also be selected on status or resources (Feliciano 2005b, 2006). We know that parents' socioeconomic standing is among the most important predictors of children's outcomes (Coleman et al. 1966). Yet, survey research has been surprisingly oblivious to the resources that immigrant parents bring.

\section{Previous studies of immigrant educational selectivity}

In a series of seminal publications, Feliciano $(2005 \mathrm{~b}, 2006)$ has elaborated the view that understanding immigrants' status at origin is crucial in assessing their children's progress. Immigrants who hold low-qualified or low-income jobs in the destination may nevertheless have a culture or habitus associated with higher class origins, if they have been downwardly mobile (cf. Rooth and Ekberg 2006; Redstone Akresh 2008).

Unlike occupation or income, educational attainment usually does not change as a consequence of migration, but its interpretation might (Feliciano 2005b; Ichou 2014). Countries differ in aggregate levels of education, so that a given level of education can signal a different standing in sending and receiving countries. This has motivated interest in educational selectivity - that is, immigrants' relative rank in the stratification system at origin - as an indirect measure of pre-migration social status.

Previous research finds that most groups tend to be positively selected on education (Feliciano 2005a; Lessard-Phillips et al. 2014), and that this seems to promote their children's schooling (Feliciano 2005b; Ichou 2014; Feliciano and Lanuza 2017). Feliciano's initial study (2005a) used 32 source countries to calculate Lieberson's (1976) net difference index: the probability that a migrant from a given country is more educated than someone who stayed. Later studies found positive associations of this index with education in the second generation 
(Feliciano 2005b, 2006). More recent work has turned to measures of individual rank in the source country's educational distribution, but with similar conclusions (Ichou 2014; Feliciano and Lanuza 2017).

A limitation of existing studies is that, by focusing mostly on children's final educational attainment, they have only indirectly addressed mechanisms. Even so, theoretical proposals abound. Feliciano hypothesized that "immigrants who were of high status in the home country may facilitate the achievement of the next generation in order to attain a similar class position" (2005b:844) and that "identities of highly educationally select immigrant groups may be based on a sense that they are entitled to mainstream success" (2006:295-96). Similarly, Ichou (2014) mentions "subjective social status" as one transmission channel. Following the idea that migrants self-select on ambition (Jasso and Rosenzweig 2006; Portes and Rumbaut 2006), selectivity may also capture a personality that propelled parents to a given level of education.

This suggests that aspirations would account for much of the association, which fits well with observed patterns of ethnic (dis)advantage. At the same time, the literature has also stressed performance-based mechanisms. For example, Ichou (2014:751) writes:

Immigrants with high levels of relative education are likely to possess academically useful resources ... comprising both cognitive skills (such as familiarity with written language and abstract reasoning) and non-cognitive skills (such as motivation and taste for academic studies).

Similarly, Feliciano and Lanuza (2017:214) argue that attaining a given level "may ... require more cognitive skills" in a context where that level is reserved for a select few, or where compulsory schooling prepares directly for the labor market.

Incidentally, this notion fits well with economic narratives of immigrants' labor market assimilation where presumed self-selection on "ability" or "skill" is sometimes proxied for by relative education (e.g., Chiquiar and Hanson 2005). Indeed, economists Hanushek and Zhang (2009) motivate their use of a closely related measure in just this way. Arguing that "an individual of cohort $\mathrm{c}$ who completes school level s on average has higher ability than any individual of the same cohort who completes a school level less than s", they see educational rank as "effectively a broad index of ability" (p. 118).

Previous work, then, suggests two main channels by which immigrants' educational rank at origin may influence their children's schooling: class-based aspirations expressed through choices at critical junctures in the education cycle, and transmission of academic skills promoting children's performance. As I shall argue next, evidence on international differences in schooling makes one of these explanations stand out as more plausible than the other. 
In any society, schooling performs two vital functions. On the one hand, schools are sorting machines, allocating individuals to positions (Hirsch 1976; Collins 1979). On the other, they instill knowledge, skills, and dispositions needed for productive social participation (Hout 2012). The latter process is not zero-sum, and therefore should be closer reflected in absolute levels of education, not relative. To understand the advantages of a high relative education, we would therefore do well to examine the process of selection.

A classical motif in historical macrosociology holds that when schooling expands, it selects increasingly on merit and less on inherited privilege (Blau and Duncan 1967; Treiman 1970). Although this narrative has been questioned (Bourdieu and Passeron [1977] 1990; Raftery and Hout 1993; Lucas 2001), there is by now little doubt that, in its broad outlines, it is supported (Breen et al. 2009). While recent immigrants come from a range of institutional contexts, these contexts mostly predate this educational democratization. Indeed, countries with a colonial past may even have inherited systems deliberately designed for local elites (Torche 2014). This suggests that in many countries of origin, education has an important role as a gatekeeper for the advantaged classes.

Recent data confirm that Latin America, Africa, and the Middle East - some of the dominant regions of origin - fare poorly on intergenerational education mobility (Narayan et al. 2018). For many countries, mobility stalled in the 1960s at much lower rates than in the West where it has continued to rise (ibid.). Educational inheritance also tends to be strongly linked to income persistence (Narayan et al. 2018:144), a situation referred to by Torche (2014:636) as "inherited meritocracy". Even so, could it be as Feliciano and Lanuza (2017:214) claim, that pre-expansion systems offer more rigorous instruction? While possible in some cases, as a general explanation it appears less likely (Prokic-Breuer and McManus 2016; OECD 2017). In fact, learning in many poor countries has been found so wanting that there is recent concern about a "global learning crisis" (OECD 2017; World Bank 2018).

This is important two reasons. First, strong intergenerational persistence is linked, conceptually and empirically, to low levels of merit selection. Consequently, a high relative education will be less indicative of the cognitive and non-cognitive skills that we usually think of as markers of educational success. Second, strong inheritance means that those with a high relative education will expect their children to reproduce their advantage. For these reasons, children of educationally select immigrants may carry high expectations of success, but find themselves poorly equipped to compete in a system of mass schooling where most peers are from homes with a higher absolute level of education.

\section{This study and its institutional context}

The empirical setting of this study is Sweden, a country where a relatively liberal immigration regime coexists with an open education system and generous welfare provision buffering 
families from the most dire consequences of poverty (Erikson and Jonsson 1996; Hällsten 2011; Jackson et al. 2012).

Since the 1970s, Swedish immigration has consisted mainly of refugees and their kin. The country is among the top OECD receivers of asylum claims (UNHCR 2016). In younger cohorts, about 25 percent have either immigrated or have at least one parent who did. These figures are in the upper range of advanced economies (OECD 2016). Absence of specific institutional ties through, say, geographical affinity (as in the U.S.-Mexico case), a colonial past (France and West Africa), or systematic labor migration (Germany and Turkey) means that immigration to Sweden is also exceedingly diverse. In this sense, the country represents a microcosm of global migration with rich source country variation (OECD 2016; see online appendix Table 1).

Like the U.S., Sweden has been a forerunner in educational expansion and both countries rank above the OECD average in tertiary attainment (OECD 2017:44). Another common feature is late tracking, which in Sweden occurs at age 15 with the end of compulsory schooling (Jackson et al. 2012). In contrast to the U.S., however, schooling at all levels is publicly funded and a universal system of student aid minimizes economic constraints on schooling continuation decisions (Hällsten 2011). Hence, educational choices are relatively unfettered both by social origin and prior achievement. This, together with a high degree of general welfare, makes Sweden one of the countries where educational inequalities are least pronounced (Erikson and Jonsson 1996; OECD 2017).

Following previous work, I focus on outcomes around age 15 (Jackson et al. 2012; Heath and Brinbaum 2014). Feliciano and Lanuza (2016) suggest that outcomes at this age may better capture resources in the family of origin than later, when they often reflect the trajectory of study embarked upon (cf. Raleigh and Kao 2010). Over 90 percent of students make the transition to secondary education at this stage (Erikson and Rudolphi 2010; Jonsson and Rudolphi 2011), but a separation exists between vocational and academic tracks.

\section{Data, measures, and methods}

The main data source for this study is administrative registers used in previous research (Hällsten 2011; Jackson et al. 2012). Linkage across registers and identification of family ties are made possible by a unique identification number that each Swedish resident uses in dealings with public services. These data are complemented with the recent Children of Immigrants Longitudinal Study in Four European Countries (CILS4EU) - which, following ethical approval, was linked to anonymized administrative data by Statistics Sweden (Kalter et al 2013; Engzell and Jonsson 2015).

In a first step, I compile administrative data on the universe of immigrant parents whose children finished compulsory school in 2008-2012. These cohorts range from $\mathrm{N}=115,655$ to $\mathrm{N}=155,290$, yielding a total sample of $\mathrm{N}=686,621$, of which $\mathrm{N}=113,775$ children of immigrants. Restricting analysis to parents who immigrated beyond age 25 , to make it 
plausible that the highest education was completed in the country of origin, yields an analytical sample of $\mathrm{N}=77,767$. I use these data to provide descriptives, and later when assessing selectivity's consequences for adjusted group comparisons.

The Swedish CILS4EU consists of a stratified random sample of the most recent cohort in the register data. Schools were drawn with a probability proportional to size, downweighting those with less than 10 percent minority pupils. About two classes in each school were randomly selected and surveyed twice in the last years of compulsory school (in 2010-2011 and 2011-2012). Restricted-use files contain administrative data allowing for the same analyses as for the full population. In addition, classroom interviews gathered data on cognitive skill, language proficiency, self-reported behavior, attitudes, and aspirations.

The survey sample amounts to $\mathrm{N}=5,025$ children nested in 228 school classes ( 126 schools). Restricting analyses to children with two immigrant parents leads to an effective size of $\mathrm{N}=$ 1,672. To avoid an excessive loss of cases I employ less restrictive selection criteria in the survey data, including childhood immigrants in both the parent and child generation (that is, I do not restrict by age at immigration but instead include it as a control variable). Results in an online appendix demonstrate that these cases represent a minority of the sample, and apart from increasing statistical power their inclusion does not greatly affect the results.

In addition, to measure educational selectivity I use Barro and Lee's (2013) database on worldwide educational attainment. The Barro-Lee data report educational distributions by gender and cohort in 5-year intervals for populations in 146 countries. Information comes from UN Demographic Yearbooks, UNESCO Statistical Yearbooks, and national statistical publications with interpolation for missing years. It is arguably the most comprehensive source of such data available, and has been used in previous studies of educational selectivity (Ichou 2014; Feliciano and Lanuza 2017).

Whereas missingness in the register data is virtually nonexistent, item nonresponse in the survey sample is a concern; see Table 1. To handle this, models are estimated using full information maximum likelihood (FIML). Like the more common method of multiple imputation (MI), FIML incorporates a model for the missing data, the main difference being that FIML embeds this model within the regression likelihood function and performs estimation in a single step. Both methods are consistent under the same assumptions, but FIML outdoes MI in terms of efficiency (Allison 2012).

\section{Parental education: absolute and relative}

The data on parental education stem from the Swedish Education Register (UREG). This population register draws on multiple sources, but for immigrants of adult age the most important ones are interviews from the last Census in 1990, and special immigrant surveys conducted by Statistics Sweden first in 1995 and then annually since 1999 (Statistics Sweden 
2011). ${ }^{1}$ Additional data are gathered from public services such as the Unemployment Agency (Arbetsförmedlingen), Introductory Language Training (SFI), Municipal Adult Education (Koтvих), or through validation of foreign credentials by the Higher Education Authority (HSV). The multiple sources entail that information is missing for less than 5 percent of the current sample - an important strength as survey response among immigrants is often low (Laganà et al. 2013; Engzell and Jonsson 2015).

The register provides a detailed version of the international ISCED-97 classification consisting of 50 levels (SUN2000), from which I construct two separate measures. First, I assign an approximate years of schooling to each level, ranging from "Compulsory education shorter than 9 years" (here assigned 5 years) to "Doctoral degree" (20 years). To assess educational selectivity I collapse the original levels into 7, corresponding to the detail of Barro and Lee's (2013) data. I then calculate the average cumulative proportion or ridit (Bross 1958; Agresti 2010) reflecting each parent's percentile in the source country's education distribution.

For this measure, two components are needed: a person's educational category $\mathrm{j} \in 1,2, \ldots, \mathrm{J}$, and the proportion of individuals within a relevant reference group belonging to each of the $\mathrm{J}$ categories. The reference group is defined as persons of the same gender born within a five year window in the sending country, and a percentile assigned as:

$$
\pi_{i j}=\left(\sum_{j^{*}<j} p_{j^{*}}+\frac{1}{2} p_{j}\right) \times 100
$$

where $p_{-} j$ indicates the proportion of the reference group with attainment level $j$. In other words, I take those who are lower educated plus half those with an equivalent education. The resulting measure ranges from 0 to 100 save for truncation due to the coarseness of observed

\footnotetext{
${ }^{1}$ This survey, "Education in a country other than Sweden", is conducted by postal questionnaire and accompanied by a translation in English as well as some of the 15 most important minority languages: Arabic; Bosnian/Croatian/Serbian; Chinese; Finnish; French; German; Persian; Polish; Romanian; Russian; Somali; Spanish; Thai; Tigrinya; Turkish (see http://www.scb.se/ual). Yearly response rates are typically in the range $50-60 \%$, but lower in some years (Statistics Sweden 2011:24-28). Repeated surveying entails that the cumulative response is higher. An inquiry into the register sources suggests that this questionnaire accounts for slightly over a third of the total information on record for the population concerned. The next most important source is unemployment agency records, at about $15 \%$, followed by the Census with a slightly lower proportion - the remainder being distributed across a large number of governmental bodies or continuing education institutions. I am indebted to Martin Hällsten for pointing me to these data.
} 
categories. ${ }^{2}$ In later analyses, I construct corresponding variables for native-born parents and here the same procedure is used, that is, relative education is based on the estimates reported by Barro and Lee (2013) for Sweden.

For both years of schooling and educational selectivity, the variable used in analyses is an average of both parents' values (alternatively, the only non-missing). This approach has the virtue of minimizing multicollinearity and missing data, increasing statistical efficiency. A more conventional approach to aggregation is to use the parent with highest education (Erikson 1984; Feliciano and Lanuza 2017). There is good methodological reason to eschew this approach, as it risks assigning undue influence to fathers (Beller 2009; Hout 2018), and is prone to measurement error and ceiling effects (Thaning and Hällsten 2018); however, the results are similar with this coding, as analyses in an online appendix show.

\section{Ethnic origin and other covariates}

Information about parents' country of birth and year of immigration is from the Register of the Total Population (RTB). Some countries with small numbers have been collapsed to preserve anonymity, and in this case I use a population-weighted average to estimate the educational rank. ${ }^{3}$ Analyses using the survey subsample rely on more detailed self-reports and are not subject to this problem. I also define a grouped region-of-origin variable following the protocol of Jackson et al. (2012), used both as a control variable and to estimate ethnic disparities in subsequent analyses. The categories are shown in Table 1.

Children of intermarriage (i.e., one parent Swedish-born) are excluded. Some children also have immigrant parents from different countries; these are dropped from the register-based analyses, but kept in the survey-based sample to avoid loss of cases. Here, region is assigned based on the country closest to Sweden if such a judgment is possible, else mother's country of birth (cf. Jackson et al. 2012). One rationale for assigning origin based on the closest parent is that forming a union outside the own group can itself be considered an indicator of integration into the new context; hence, the closer parent is expected to better reflect the

\footnotetext{
2 In countries with very low or high levels of schooling, the lower (upper) bound can in practice be quite far from $0(100)$, inducing a negative correlation between selectivity and aggregate educational development. It is possible to correct for this by a simple transformation $\backslash$ pi_ $\{\text { ij }\}^{\wedge *}=\mid$ frac $\left\{\left|p i \_\{i j\}-\right| p i \_1\right\}\left\{\left|p i \_J-\right| p i \_1\right\}$, where pi_1 and pi_J are the cumulative proportions in the bottom and top categories and pi_\{ij $\}^{\wedge *}$ is the rescaled measure. For consistency with previous studies I have not applied this transformation, but results remain substantively similar with it. Another issue arises as to what data point to use for each given cohort since the Barro-Lee data are provided in time-series format. I have used the latest observation (2010) but alternative procedures such as selecting on the year the parent turned 25, or the year of parent's immigration, yields measures correlated at $r>.95$ and essentially identical results.

${ }^{3}$ A number of countries are also lacking from the Barro-Lee dataset (notably, Ethiopia, Eritrea, Lebanon, Palestine, Somalia), in these cases a population-weighted average of the surrounding region is used. Excluding these countries does not alter the substantive conclusions.
} 
couple's attachment to, and resources within, the host society. However, the implications are minor: of $\mathrm{N}=270(16 \%)$ children with parents from different countries, only $\mathrm{N}=123(7 \%)$ hail from separate regions. ${ }^{4}$

Because independent variation between the two education measures stems mainly from between-country differences in educational makeup, a worry is that they might pick up unobserved source country characteristics that are independently associated with children's outcomes. To alleviate this concern, three strategies are used. First, I enter the average years of schooling for the country and cohort as a control for macro-level development. Second, I enter the grouped origin variable as a set of fixed effects, eliminating the influence of any unobserved characteristics shared by these groups. Third, to examine whether any one country might be driving the estimates, I repeat the analyses excluding individual origin countries one at a time.

All models control for student gender and immigrant generation, based on register information. Generation is a categorical variable, defined here as: migrated before age 10, after age 10, or born in the country (see Table 1). Using parents' years of time in Sweden as a continuous variable instead, with our without polynomials, or binning the variable into 10 discrete groups did not alter the results. In addition, the online appendix presents analyses inter alia separated by gender; modelling mothers' and fathers' education separately; dropping children with non-coresident parents, dropping parents who migrated before age 25 , and dropping first generation children.

\section{Second-generation outcomes}

Outcomes are collected from a combination of register and survey data. For register data I follow previous studies that have analyzed school grades and track choice (Jonsson and Rudolphi 2011; Jackson et al. 2012). The student's final grade sum is the total score among his or her sixteen best subjects of about twenty at the end of compulsory schooling (mean 198.97, s.d. 65.47). These grades, which are teacher-assigned, are the main selection instrument in applying for post-compulsory schooling. As described above, the majority of students proceed to secondary education (gymnasium) and here a watershed exists between the two tracks that have traditionally provided general access to university, Natural Sciences (NA) and Social Sciences (SA), and those that offer narrower study options or prepare mainly for the labour market. I construct a binary indicator for application to an academic track (mean 0.42).

\footnotetext{
${ }^{4}$ It was suggested in peer review that the models may be incomplete by failing to account for race. In fact, a direct measure of "race" is not available in these data, and in Sweden as in many other non-U.S. countries there is no established practice of racial classification. Nevertheless, visible minority status is largely captured by the country-of-origin groups. In England, the CILS4EU survey included a question about ethnic self-identity, modeled on the England and Wales Census, that comes close to the American notion of "race". Parameshwaran and Engzell (2015) validate this measure against an origin-based classification and report substantial agreement.
} 
In addition, I cross-validate results against several performance and aspiration indicators available in the CILS4EU. In many ways, grades are the theoretically most appropriate measure of performance, as they are both the formal selection instrument for continued education, and the most salient signal about their own ability that students receive (Jackson et al. 2012:161). I complement this with test scores independent of the learned curriculum. As an ability measure, grades are both broader and narrower than cognitive tests. Broader because they reflect a wider palette of skills, including discipline and the exertion of sustained effort over time; narrower because they capture only a subset of students' potential that has been more or less consciously directed at school success.

The CILS4EU test of cognitive skill is similar to Raven's Progressive Matrices. Focusing on visual puzzles, it has specifically been designed to avoid cultural and linguistic bias (Weiss 2006). While this is a strength, even the purportedly most "culture-free" test is likely to contain a component of familiarity with context and cultural learning (cf. Resnick 1987, Saxe 1988). The test comprised 27 items to be completed in 7 minutes and the final score equals the number of correct answers (mean 15.8, s.d. 5.25). A similar test of Swedish language proficiency was administered at the same occasion (mean 15.2, s.d. 4.95). I use the language score as an independent outcome, but also as a control variable in robustness analyses to further alleviate concerns about language bias.

As an indicator of non-cognitive determinants of educational achievement, I measure school behavior based on the self-reported incidence of coming late to school, arguing with teacher(s), getting punished in school, and skipping lessons without permission (cf. Ainsworth-Darnell and Downey 1998; Harris and Robinson 2007). Answers are on a 5-point scale and range from "every day" to "never". I extracted the first component from a principal components analysis accounting for the ordinal nature of the response scale (Kolenikov and Angeles 2009). Additionally, I experimented with other measures of non-cognitive skill including locus of control (Groves 2005) and time preference (Golsteyn, Grönqvist, and Lindahl 2014). All these measures showed weak associations with parental education, and only results for self-reported behavior are reported here in the interest of space.

Educational decisions are subject to beliefs about own ability and the value of education (Holm and Breen 2016). A measure of students' self-assessment taps their confidence that they can "do well at school", "get good grades at school" (wave one and two), "succeed at upper secondary school, academic track", and "succeed at university" (wave two only), while the perceived value of education draws on the following items: "Education is very important for getting a good life later on", "It is very important for me to get good grades" (wave one), "University education is very important for getting a good job", "I would be willing to study at university even if it means that I have less money to live on for several years", and "To get the education I want, I would be willing to move" (wave two). For both sets of items, answers are on a 5-point scale and I retain the first polychoric principal component of each.

As part of the wave two questionnaire, career aspirations were elicited with an open question: "What occupation would you like to have as an adult?". Students were asked for an 
occupational title which was converted into International Socio-Economic Index of Occupational Status (ISEI-08) scores (Ganzeboom and Treiman 1996). Although nonresponse on this item was understandably higher than for closed-format items it is included to test the argument that educational selectivity may proxy for class origin - assuming that transmission of occupational preferences is an important conduit of class reproduction (Jonsson et al. 2009). A related set of questions about educational aspirations was omitted from analysis because, the vast majority aspiring for university, distributions were too skewed to be informative.

\section{Results}

Figure 1 provides a first look at the distribution of years of schooling and educational rank between and within immigrant groups. The top panel plots individual values on the two measures against each other, within the population of immigrant parents. There is a strong correlation at the individual level $(r=0.76)$. The bottom panel displays the same information at the group average level, with circles reflecting group size. Some of the larger groups in Table 1 have been broken up to provide additional detail. While this figure is based on population data, the distributions are similar in the survey data, as is the bivariate correlation between the two measures $(r=0.74)$.

The high individual-level correlation is contrasted by a relatively weak correspondence at the group level: the most positively selected groups are rarely the ones with highest absolute levels of schooling, and vice versa. Despite their internal differences, however, nearly all groups share two defining characteristics: they are on average more educated than the population at origin (they lie above the 50th percentile, horizontal line) but less educated than the corresponding group of native-born Swedish parents (average about 12 years, vertical line).

A few groups appear "hyperselected" (Lee and Zhou 2015) in that they score above average irrespective of the axis of comparison. This holds for Eastern European origins, including Poland, and for the small group of West European and American origins. Other groups come close, including the Iranian, a minority that has been found to outperform majority children in Sweden (Jonsson and Rudolphi 2011). The same holds for the Latin American group, at least leaving aside a sizeable Chilean minority that is slightly less positively selected on average. Both the Chilean and other Hispanic minorities represent a mix of early labor migrants, political refugees, and later family migration.

Interestingly, ethnic Asians, which tend to do well in Sweden as elsewhere, do not appear to be markedly more positively selected than other groups. In fact, they closely overlap with a large group of Iraqi origin (consisting mostly of refugees). Conversely, some of the most positively selected groups - African origins stand out at the top - are among those who tend to be disadvantaged in school grades. Several other groups fall under this description and they place themselves variously across the selectivity map: Latin America (including Chile), the Middle East (including Turkey and Iraq), former Yugoslavia (where many are refugees from 
the Balkan wars), as well as the neighboring Nordic countries where Finns are the predominant group (Jonsson and Rudolphi 2011).

I return to these group differences below, but first I leverage the considerable variation within and across groups to assess how children of immigrant origin may benefit from educational selectivity, over and above parents' absolute years of schooling. Following the studies of Feliciano (2005b, 2006) and Ichou (2014), this part of the analysis seeks to explain differences within the population children of immigrants, rather than vis-à-vis the majority (cf. Harris, Jamison, and Trujillo 2008; Levels, Dronkers, and Kraaykamp 2008).

\section{Selectivity and second-generation outcomes}

Methodological literature has failed to produce consensus on how to assess predictors' relative importance for a given outcome (Grömping 2015). In the absence of a natural metric, I display standardized beta-coefficients from multivariate regressions predicting each outcome, and calculate their associated p-values based on a z-test with standard errors clustered on school classes. ${ }^{5}$ Standardized regression coefficients are common in the literature and, arguably, intuitive to interpret but the results have also been tested robust to a number of approaches based on variance partitioning, including partial and semipartial correlations, or the ratio of explained variance in bivariate regression analyses where either of the two education measures is used.

The results, shown in Table 2, are easily summarized and not appreciably altered by controls. Contrary to speculations that educational selectivity might proxy for cognitive skill, there is no positive association between parents' relative education and the child's cognitive test score. The same pattern holds for host country language proficiency. For school behavior there is no clear association with either education measure. This is in line with previous studies that report a weak correlation of non-cognitive skills with parental characteristics (Mood, Jonsson, and Bihagen 2012), but measurement error is also a likely explanation as the measure draws on few items with skewed distributions; indeed, the low $\mathrm{R}^{\wedge} 2$ coefficients seem to suggest as much. For grades, results are reminiscent of those for test scores, with the difference that the point estimate for educational selectivity is more positive, albeit statistically insignificant.

\footnotetext{
${ }^{5}$ One reviewer suggested that it might additionally be relevant to identify siblings in the data. As parental origin and education do not vary within sibling pairs, siblings contribute no independent variation in the explanatory variables but they do increase statistical power. While it is possible to cluster standard errors at the family level as well as that of the school class, methodological literature suggests that this is appropriate only when clustering is a feature of the sampling design (Abadie et al. 2017). This would apply if, for example, mothers were randomly sampled and all their children interviewed - but not here, where the sampling frame consists of children. In any case, such adjustment would be of little practical importance: in the survey data siblings comprise less than $3 \%$ of the sample (the children are all in the same school grade), while in the register data the number of observations is so large that clustering becomes inconsequential.
} 
Thus far then, educational selectivity seems to offer little explanatory power. This picture changes once we turn from achievement measures to examine outcomes more closely related to attitudes and educational decision-making. While the estimates for academic selfassessment are inconclusive, those for perceived value of education are clearly in favour of selectivity. (However, the negative coefficient for years of schooling raises some concern about misspecification, and the low $\mathrm{R}^{\wedge} 2$ for both these outcomes suggests that measurement may be a concern.)

The pattern becomes more evident for career aspirations and application to an academically oriented track. For both these outcomes, the marginal contribution of parental years of schooling is small and non-significant, while the contribution of educational selectivity dominates. The finding for occupational aspirations is notable as it fits well with the social reproduction hypothesis of Feliciano (2005b, 2006) and Ichou (2014). More direct evidence on parents' occupational status or income rank before migration would be useful to shed further light on this issue.

While it is easy to suggest additional controls that may be relevant for these estimations, the basic point is that even with the relatively limited set of statistical controls already included, educational selectivity fails to provide explanatory power for children's performance over and above parental years of schooling, while for children's aspirations and choices it does an equal or greater amount of explanatory work. The conclusions appear robust across a series of related outcomes.

\section{Robustness analyses}

I also performed a number of alternative specifications and robustness checks. Because the discrepancies in absolute and relative education are largely driven by between-country differences, one concern is that individual countries may exert a leverage on the results. Therefore I successively dropped all observations from a given country, reestimating the regressions each time. Figure 2 plots the result for the baseline model predicting grades and transition probabilities, and confirms that results are robust.

To further preclude the possibility of language bias in the cognitive test, I also estimated associations including language proficiency as a control, with no major changes. Moreover, I ran regressions for grades controlling for test scores (cognitive and language tests). The residualized grade might be seen as a catch-all measure of traits that are rewarded in school over cognitive skills, including study habits and traits such as diligence or perseverance (but if teacher discrimination occurs it would be reflected here as well). In this specification, relative education made more of a contribution, about equal to that of years of schooling.

Another question is whether pathways of transmission are gender-specific. The online appendix reproduces Table 2, but separating boys and girls, and using education variables of the mother or father. Gender-separate results are broadly consistent with the pooled regressions. Separating mothers and fathers, the finding that selectivity lacks influence on 
performance likewise remains robust. Its influence on aspirations is somewhat more varied, however, and years of schooling rivals selectivity as a predictor of track choice in some of the more extensively controlled models.

Similar results occur for other subgroup analyses, including ones restricted to the 1.5 or 2 nd generation, or children with non-separated parents. While these nuances do not change the overall conclusions, they suggest that the influence of selectivity on track choice may be more fragile as a result than its non-influence on performance in this population. Note however that these regressions do not account for prior performance; with grades in the same model, selectivity again gains in importance for track choice.

\section{Consequences for ethnic disparities}

Much recent interest in educational selectivity appears motivated by its implications for models that compare minority achievements and attainments with those of the ethnic majority (van de Werfhorst and Heath 2018). For example, Feliciano and Lanuza (2017:223) suggest that the appearance of immigrant optimism may result from failure "to contextualize the educational attainments of immigrant parents", a variable they suggest "captures hidden dimensions of class background" (p. 232). Similarly, Luthra and Soehl (2015:564) argue that educational selectivity may provide a "more universal control" for parental resources than years of schooling.

Of course, the appropriate choice depends largely on what one wishes to control for. The above findings demonstrate that educational selectivity does not have a uniform association with children's outcomes: while it seems to matter for children's aspirations and choices, it is less consequential for their academic skills and achievement. If the choice of control is to be guided by which variable actually predicts a given outcome within the minority population, educational selectivity might be relevant to control for in analyses of students' aspirations, but less so for their cognitive achievement or grades.

To assess the implications of choosing one control over the other, Figure 3 displays estimated differences in educational performance and academic track choice for the second generation compared to children of two native-born parents. ${ }^{6}$ The left panel displays average grade sums (z-standardized), and the right panel the probability of academic track choice. To allow comparison with previous studies, transition probabilites are estimated net of grades, and some of the immigrant groups in Figure 1 have been collapsed (Jonsson and Rudolphi 2011; Jackson et al. 2012). These analyses exclude parents who migrated before age 25, children who were themselves born abroad, and children of mixed parentage. The (unconditional) differences are broadly in line with previous results for Sweden and affirming the by now familiar asymmetry between performance and choice (Heath and Brinbaum 2014).

\footnotetext{
${ }^{6}$ These estimates draw only on the two most recent cohorts to keep variable definitions consistent with survey data; a reform that took place in 2011 reconfigured the system of academic tracks (Statskontoret 2012). The number of observations is larger than in Figure 1 because native majority children are included as a reference group.
} 
Of main interest is how these estimates change when parental education is introduced, either as years of schooling or educational selectivity. As for performance (Figure 3, left panel), parental years of schooling turn out to account for about half of the achievement disadvantage among children of Nordic, African, and Latin American parentage. For groups originating in Southern Europe (including former Yugoslavia) and the Middle East (including Turkey and Iraq), their initial disadvantage is reversed to a slight advantage. Overall parental years of schooling appear to contribute greatly to explaining differences in children's achieved grades. The notable exception is the Asian group, whose advantage increases with years of schooling held constant, to about twice its size.

In contrast, controlling for educational selectivity in grade achievement yields dramatically different results. Many of the groups disadvantaged in performance remain so (Nordic, Southern Europe, Middle East, Latin America). Here, the negative gap for the African origin group expands to twice its original size. The Iranian group goes from outperforming the majority to lagging behind. The group of East European origin (including Poland) likewise shows a net disadvantage, visible already with absolute education controls, but absent in the baseline model.

Based on these results, we might think that the educational system is failing some of these groups badly. Yet, given knowledge that educational selectivity does not contribute to achievement differences within these minorities it is not clear what we learn by "controlling" for it in this way. In fact, the results from the previous section suggest that controlling for educational selectivity will mainly be relevant in understanding the dynamics behind aspirations and educational choice, which I turn to next.

Figure 3, right panel, extends these analyses to track choice. Consistent with prior research, ethnic advantages are large; at given levels of performance, many groups are between 10 and 25 percentage points more likely to opt for academic education than the majority. If controlling for years of schooling reduced achievement disparities, the reverse holds in this case: the advantages of South European, Middle Eastern, and Asian minorities show a significant increase from the first to the second model with years of schooling held constant. This finding is consistent with the well established result that minority advantage often appears first when conventional measures of social origin are controlled for (Heath and Brinbaum 2014; Feliciano and Lanuza 2017).

Controlling for selectivity, the minority advantage in application behavior remains substantial for all non-European groups but the Latin American. However, it is approximately halved in size in some groups (West, Iran, Africa) and visibly reduced in others (Middle East, Asia). On balance, the findings suggest that educational selectivity, or whatever parental characteristics it proxies for, goes some way toward explaining the high aspirations of immigrant youth. Yet, most of the minority advantage in aspirations actually persists when taking educational selectivity into account. 
It would be tempting to attribute this residual "immigrant optimism" to factors independent of social background, but it bears noting that the relative education rank is at best a weak proxy for concepts that are more sociologically meaningful. If taken to reflect the place in a continuous education distribution, for example, it is inevitably constrained by the number of measured categories. A similar argument applies if seen as a proxy for social class before migration, in which case, e.g., income and occupation remain unobserved. Further research and above all, better measures of status at origin - are needed to shed light on the role of selective migration for immigrant optimism, but results here certainly suggest a nexus between the two.

\section{Conclusion}

This article has bridged two major topics in the study of the educational careers of children from immigrant families: the commonly observed (but not universal) asymmetry between low performance and high aspirations (Jackson et al. 2012), and immigrant selectivity and its consequences (Ichou 2014; Feliciano and Lanuza 2017). In particular, recent contributions highlight the context-dependence of what constitutes a "high" level of education and its attendant privileges - showing that relative rank at origin matters for children's schooling. Yet, these works only indirectly addressed mechanisms.

Two views exist on how immigrants' educational rank at origin may affect children's schooling. On one view, a desire to make up for status that parents have lost in migration explains the association (Feliciano 2005b, 2006). Alternatively, unobserved cognitive and non-cognitive skills that led parents to attain a given level of education could be behind it. Comparative and historical evidence makes the former of these explanations seem more plausible. Schooling in countries with less expansive systems tends to be marked by precarious quality, uneven access, and strong inheritance (Torche 2014; Narayan et al. 2018; World Bank 2018), limiting the potential skill benefits of a high relative rank.

Using data from Sweden, I tested the implication that parents' educational selectivity may confer high expectations but only limited means to attain it. This hypothesis found support across several outcomes: parents' educational selectivity outdoes parental years of schooling as a predictor of adolescents' attitudes, aspirations, and and choices, but is of limited relevance for their test scores and school grades when years of schooling are taken into account. In other words, skill transmission appears to play a minor role, if any, in these patterns and what stands out are instead aspirations and educational choices.

These findings nuance those of Ichou (2014) and Feliciano and Lanuza (2017) who find that parents' absolute and relative education both matter for children's final educational attainment, which represents the combined influence of performance and choice. From a theoretical point of view, results are consistent with the notion that educational selectivity might be tapping a wider class construct, exerting its influence through perceptions, values, and expectations cultivated within the family (Feliciano 2005b; Ichou 2014). An important future task is to examine data on other aspects of parental status prior to migration. Transnational occupation 
histories are now available in several surveys and should prove valuable for this purpose (Pong and Landale 2012; Fellini and Guetto 2018).

Going further, this study also assessed educational selectivity as an overall explanation for the phenomenon of "immigrant optimism" in educational choices. Here it was found that an important part of the minority advantage persists with educational selectivity in the model. It is possible that this advantage would shrink further with more stringent controls for premigration status, if observed. But other explanations may also exist. For one thing, selectivity is a complex construct that comprises not only education, or even status broadly conceived, but also unobserved personality traits such as ambition, that may or may not be correlated with observable measures.

Additionally, the literature provides many other mechanisms, which should be seen as complementary. These include: sacrifices associated with migration (Suárez-Orozco and Suárez-Orozco 2001; Smith 2008); resources embedded in co-ethnic networks (Zhou and Bankston 1994; Zhou and Kim 2006); parental control and monitoring (Goyette and Xie 1999; Glick and White 2004; Raleigh and Kao 2010); desire to avoid ethnic discrimination (Sue and Okazaki 1990); or underestimation of obstacles to academic success (Kao and Tienda 1998; Konczal and Haller 2008). Another important consideration is how individuallevel processes such as educational selection may create endogenous group-level dynamics or interact with the community or context of reception (Lee and Zhou 2015; van de Werfhorst and Heath 2018).

A methodological conclusion is that adjusted comparisons of ethnic educational disparities are highly dependent on how parental education is conceptualized. Preferring a particular operationalization without a strong idea of what one intends to control for might therefore produce results that are misleading. It is notable that not only the size of estimates might differ, but also their sign - leading to divergent conclusions. This is broadly in line with Luthra and Soehl (2015:563) who note, for independent reasons, that adjusting for parental education in models of ethnic (dis)advantage "may be a statistical exercise of dubious value". Results in this study suggest that absolute educational controls may be more relevant in accounting for cognitive resources in the home and differences in children's performance, whereas educational selectivity may be a more meaningful control for aspiration levels.

It remains to be seen how these results generalize beyond the context studied here. In one way, Sweden represents a best-case scenario of what can be achieved with generous public services, fully subsidized education, and a system with few academic dead ends. At the same time, this does not eradicate problems such as housing and school segregation which have risen in recent years (Böhlmark, Holmlund, and Lindahl 2016; Östh, Andersson, and Malmberg 2013). Immigrants to Sweden also face a particular challenge as few of them arrive with prior knowledge of the language. An important future task is to examine how far the conclusions reached here carry over to other countries of destination, including the U.S. and France that previous studies have focused on. 
At a theoretical level, this study highlights the need to understand the stratification regimes that immigrants have left behind in their countries of origin in the study of immigrant incorporation. Indeed, the national differences outlined here - with more restricted access and high educational returns in many countries of origin - might explain why immigrant parents would want their children to reap the benefits of a more open system, quite regardless of their own social origin. An interesting avenue for future research would be to bring more systematic data on sending countries' stratification regimes into the picture in attempting to explain their children's trajectories in the new country.

\section{References}

Abadie, Alberto, Susan Athey, Guido W. Imbens, and Jeffrey Wooldridge. (2017). When Should You Adjust Standard Errors for Clustering? NBER Working Paper 24003, National Bureau of Economic Research.

Agresti, Alan (2010). Analysis of Ordinal Categorical Data, 2nd edn. New York: Wiley.

Ainsworth-Darnell, James W., and Douglas B. Downey. (1998). Assessing the oppositional culture explanation for racial/ethnic differences in school performance. American Sociological Review, 63(4), 536-553.

Alba, Richard, and Jennifer Holdaway (eds.). (2013). The Children of Immigrants at School: A comparative look at integration in the United States and Western Europe. NYU Press.

Alba, Richard, and Victor Nee. (2003). Remaking the American mainstream: Assimilation and contemporary America. Harvard University Press.

Alba, Richard, Jennifer Sloan, and Jessica Sperling (2011). The Integration Imperative: The children of low-status immigrants in the schools of wealthy societies. Annual Review of Sociology, 37, 395-415.

Alba, Richard, and Mary C. Waters (eds.). (2011). The Next Generation: Immigrant youth in a comparative perspective. NYU Press.

Allison, Paul D. (2012). Handling Missing Data by Maximum Likelihood. Manuscript.

Barro, Robert J., and Jong Wha Lee (2013). A New Data Set of Educational Attainment in the World, 1950-2010. Journal of Development Economics, 104, 184-198.

Beller, Emily (2009). Bringing intergenerational social mobility research into the twenty-first century: Why mothers matter. American Sociological Review, 74(4), 507-528. 
Blau, Peter M., and Otis Dudley Duncan (1967). The American occupational structure. New York: John Wiley \& Sons.

Böhlmark, Anders, Helena Holmlund, and Mikael Lindahl (2016). Parental Choice, Neighbourhood Segregation or Cream Skimming? An analysis of school segregation after a generalized choice reform. Journal of Population Economics, 29 (4), 1155-1190.

Boudon, Raymond (1974). Education, opportunity, and social inequality: Changing prospects in western society. New York: John Wiley \& Sons.

Bourdieu, Pierre and Jean-Claude Passeron. ([1977] 1990). Reproduction in Education, Society and Culture. London: Sage.

Breen, Richard, and Jan O. Jonsson (2007). Explaining Change in Social Fluidity: Educational equalization and educational expansion in twentieth-century Sweden. American Journal of Sociology, 112(6), 1775-1810.

Breen, Richard, Ruud Luijkx, Walter Müller, and Reinhard Pollak (2009). Nonpersistent Inequality in Educational Attainment: Evidence from eight European countries. American Journal of Sociology, 114(5), 1475-1521.

Bross, I. D. J., (1958). How to Use Ridit Analysis. Biometrics, 14(1), 18-38.

Casey, Teresa, and Christian Dustmann (2008). Intergenerational transmission of language capital and economic outcomes. Journal of Human Resources, 43(3), 660-687.

Chiquiar, Daniel, and Gordon H. Hanson. (2005). International migration, self-selection, and the distribution of wages: Evidence from Mexico and the United States. Journal of Political Economy, 113(2), 239-281.

Coleman, James S., et al. (1966). Equality of Educational Opportunity. Washington: U.S. Department of Health, Education, and Welfare, Office of Education.

Collins, Randall (1979). The Credential Society: An Historical Sociology of Education and Stratification. New York: Academic Press.

Crul, Maurice, Jens Schneider, and Frans Lelie (2012). The European Second Generation Compared: Does the integration context matter? Amsterdam University Press.

Diehl, Claudia, et al. (2016). Causes and Consequences of Socio-Cultural Integration Processes among New Immigrants in Europe (SCIP). doi: 10.4232/1.12341 
Engzell, Per, and Jan O. Jonsson (2015). Estimating social and ethnic inequality in school surveys: biases from child misreporting and parent nonresponse. European Sociological Review, 31(3), 312-325.

Erikson, Robert (1984). Social Class of Men, Women and Families. Sociology, 18(4), 500-514.

Erikson, Robert and Jan O. Jonsson (1996). Can Education be Equalized? Boulder: Westview Press.

Erikson, Robert, and Frida Rudolphi (2010). Change in Social Selection to Upper Secondary School: Primary and secondary effects in Sweden. European Sociological Review, 26(3), 291-305.

Feliciano, Cynthia (2005a). Educational Selectivity in U.S. Immigration: How do immigrants compare to those left behind? Demography, 42(1), 131-152.

Feliciano, Cynthia (2005b). Does Selective Migration Matter? Explaining ethnic disparities in educational attainment among immigrants' children. International Migration Review, 39(4), 841-871.

Feliciano, Cynthia (2006). Beyond the Family: The influence of pre-migration group status on the educational expectations of immigrants' children. Sociology of Education, 79(4), 281303.

Feliciano, Cynthia, and Yader R. Lanuza (2016). The Immigrant Advantage in Adolescent Educational Expectations. International Migration Review, 50(3), 758-792.

Feliciano, Cynthia, and Yader R. Lanuza (2017). An Immigrant Paradox? Contextual attainment and intergenerational educational mobility. American Sociological Review, 82(1), 211-241.

Fellini, Ivana, and Raffaele Guetto (2018). A "U-Shaped" Pattern of Immigrants' Occupational Careers? A Comparative Analysis of Italy, Spain, and France. International Migration Review, forthcom. doi: 10.1177/0197918318767931

Ganzeboom, Harry B., and Donald J. Treiman (1996). Internationally Comparable Measures of Occupational Status for the 1988 International Standard Classification of Occupations. Social Science Research, 25, 201-239.

Glick, Jennifer E., and Michael J. White (2004). Post-secondary school participation of immigrant and native youth: The role of familial resources and educational expectations. Social Science Research, 33(2), 272-299. 
Golsteyn, Bart H.H., Hans Grönqvist, and Lena Lindahl (2014). Adolescent Time Preferences Predict Lifetime Outcomes. Economic Journal, 124(580), F739-F761.

Goyette, Kimberly, and Yu Xie (1999). Educational expectations of Asian American youths: Determinants and ethnic differences. Sociology of Education, 72(1), 22-36.

Grömping, Ulrike (2015). Variable Importance in Regression Models. Wiley Interdisciplinary Reviews: Computational Statistics, 7(2), 137-152.

Groves, Melissa O. (2005). Personality and the Intergenerational Transmission of Economic Status. Ch. 7 in Bowles, S., Gintis, H., Groves, M. O. (eds.), Unequal Chances: Family background and economic success. Princeton University Press.

Hällsten, Martin (2011). The Structure of Educational Decision Making and Consequences for Inequality: A Swedish test case. American Journal of Sociology, 116 (3), 806-54

Hanushek, Eric A., and Lei Zhang (2009). Quality-Consistent Estimates of International Schooling and Skill Gradients. Journal of Human Capital, 3(2), 107-143.

Harris, Angel L., Kenneth M. Jamison, and Monica H. Trujillo (2008). Disparities in the Educational Success of Immigrants: An assessment of the immigrant effect for Asians and Latinos. Annals of the American Academy of Political and Social Science, 620(1), 90-114.

Harris, Angel L., and Keith Robinson (2007). Schooling behaviors or prior skills? A cautionary tale of omitted variable bias within oppositional culture theory. Sociology of Education, 80(2), 139-157.

Heath, Anthony F., and Yaël Brinbaum (eds.) (2014). Unequal Attainments: Ethnic educational inequalities in ten Western countries. Oxford University Press for the British Academy.

Heath, Anthony F., and Sin Yi Cheung (eds.) (2007). Unequal Chances: Ethnic minorities in Western labour markets. Oxford University Press for the British Academy.

Heath, Anthony F., and Neli Demireva (2014). Has Multiculturalism Failed in Britain? Ethnic and Racial Studies, 37(1), 161-180.

Heath, Anthony F., Catherine Rothon, and Elina Kilpi (2008). The Second Generation in Western Europe: Education, unemployment, and occupational attainment. Annual Review of Sociology, 34, 211-235.

Hirsch, Fred (1976). Social Limits to Growth. Harvard University Press. 
Hirschman, Charles (2001). The educational enrollment of immigrant youth: A test of the segmented-assimilation hypothesis. Demography, 38(3), 317-336.

Holm, Anders, and Richard Breen (2016). Behavioral and Statistical Models of Educational Inequality. Rationality and Society, 28(3), 270-298

Hout, Michael (2012). Social and Economic Returns to College Education in the United States. Annual Review of Sociology, 38, 379-400.

Hout, Michael (2018). Americans' Occupational Status Reflects the Status of Both of their Parents. Proceedings of the National Academy of Sciences, early access. doi: 10.1073/pnas. 1802508115.

Ichou, Mathieu (2014). Who They Were There: Immigrants' educational selectivity and their children's educational attainment. European Sociological Review, 30(6), 750-765.

Jackson, Michelle (2012). Bold Choices: How ethnic inequalities in educational attainment are suppressed. Oxford Review of Education, 38(2), 189-208.

Jackson, Michelle (2013). Determined to Succeed? Performance versus Choice in Educational Attainment. Stanford University Press.

Jackson, Michelle, Jan O. Jonsson, and Frida Rudolphi (2012). Ethnic Inequality in Choicedriven Education Systems: A longitudinal study of performance and choice in England and Sweden. Sociology of Education, 85(2), 158-178.

Jasso, Guillermina, and Mark R. Rosenzweig (2006). Characteristics of Immigrants to the United States: 1820-2003. Ch. 15 in Ueda, R. (ed.), A Companion to American Immigration. New York: John Wiley.

Jonsson, Jan O., David B. Grusky, Matthew Di Carlo, Reinhard Pollak, and Mary C. Brinton (2009). Microclass Mobility: Social reproduction in four countries. American Journal of Sociology, 114(4), 977-1036.

Jonsson, Jan O., and Frida Rudolphi (2011). Weak Performance - Strong Determination: School achievement and educational choice among children of immigrants in Sweden. European Sociological Review, 27(4), 487-508.

Kalter, Frank, et al. (2013). Children of Immigrants Longitudinal Survey in Four European Countries (CILS4EU). doi: 10.4232/cils4eu.5353.1.0.0.

Kao, Grace, and Jennifer S. Thompson (2003). Racial and Ethnic Stratification in Educational Achievement and Attainment. Annual Review of Sociology, 29, 417-442. 
Kao, Grace, and Marta Tienda (1995). Optimism and Achievement: The educational performance of immigrant youth. Social Science Quarterly, 76, 1-19.

Kao, Grace, and Marta Tienda (1998). Educational Aspirations of Minority Youth. American Journal of Education, 106, 349-384.

Keller, Ursula, and Kathryn Harker Tillman (2008). Post-secondary educational attainment of immigrant and native youth. Social Forces, 87(1), 121-152.

Kolenikov, Stanislav, and Gustavo Angeles (2009). Socioeconomic Status Measurement with Discrete Proxy Variables: Is principal component analysis a reliable answer? Review of Income and Wealth, 55(1), 128-165.

Konczal, Lisa, and William Haller (2008). Fit to miss, but matched to hatch: Success factors among the second generation's disadvantaged in South Florida. Annals of the American Academy of Political and Social Science, 620(1), 161-176.

Kroneberg, Clemens (2008). Ethnic communities and school performance among the new second generation in the United States: Testing the theory of segmented assimilation. Annals of the American Academy of Political and Social Science, 620(1), 138-160.

Laganà, Francesco, Guy Elcheroth, Sandra Penic, Brian Kleiner, and Nicole Fasel (2013). National Minorities and their Representation in Social Surveys: Which practices make a difference? Quality and Quantity, 47(3), 1287-1314.

Lee, Everett S (1966). A Theory of Migration. Demography, 3(1), 47-57.

Lee, Jennifer, and Min Zhou (2015). The Asian American Achievement Paradox. Russell Sage Foundation.

Lessard-Phillips, Laurence, Fenella Fleischmann, and E. J. van Elsas (2014). Ethnic Minorities in Ten Western Countries: Migration flows, policies and institutional differences. Ch. 2 in Heath, A. F., Brinbaum, Y. (eds.), Unequal Attainments. Oxford University Press.

Levels, Mark, Jaap Dronkers, and Gerbert Kraaykamp (2008). Immigrant Children's Educational Achievement in Western Countries: Origin, destination, and community effects on mathematical performance. American Sociological Review, 73(5), 835-853.

Lieberson, Stanley (1976). Rank-Sum Comparisons Between Groups. Sociological Methodology, 7, 276-291.

Lucas, Samuel R. (2001). Effectively Maintained Inequality: Education transitions, track mobility, and social background effects. American Journal of Sociology, 106(6), 1642-1690. 
Luthra, Renee Reichl, and Thomas Soehl (2015). From Parent to Child? Transmission of educational attainment within immigrant families: Methodological considerations. Demography, 52(2), 543-567.

Lutz, Amy (2007). Barriers to high-school completion among immigrant and later-generation Latinos in the U.S.A: Language, ethnicity and socioeconomic status. Ethnicities, 7(3), 323-342.

Mood, Carina, Jan O. Jonsson, and Erik Bihagen (2012). Socioeconomic Persistence across Generations: Cognitive and non-cognitive processes. Ch. 3 in Ermisch, J., Jäntti, M., Smeeding, T.M. (eds.), From Parents to Children: The intergenerational transmission of advantage. Russell Sage Foundation.

Narayan, Ambar, Roy Van der Weide, Alexandru Cojocaru, Christoph Lakner, Silvia Redaelli, Daniel Gerszon Mahler, Rakesh Gupta N. Ramasubbaiah, and Stefan Thewissen (2018). Fair Progress?: Economic Mobility across Generations around the World. Washington, DC: World Bank.

OECD [Organisation for Economic Co-operation and Development] (2016). Working Together: Skills and labour market integration of immigrants and their children in Sweden. Paris: OECD Publishing. doi: 10.1787/9789264257382-en

OECD [Organisation for Economic Co-operation and Development] (2017). Education at a Glance 2017: OECD Indicators. Paris: OECD Publishing. 10.1787/eag-2017-en

Östh, John, Eva Andersson, and Bo Malmberg (2013). School Choice and Increasing Performance Difference: A counterfactual approach. Urban Studies, 50(2), 407-425.

Parameshwaran, Meenakshi, and Per Engzell (2015). Ethnicity in England: What Parents' Country of Birth Can and Can't Tell Us about Their Children's Ethnic Identification. Journal of Ethnic and Migration Studies, 41(3), 399-424.

Pong, Suet-ling, and Nancy S. Landale (2012). Academic Achievement of Legal Immigrants' Children: The Roles of Parents' Pre- and Postmigration Characteristics in Origin-Group Differences. Child Development, 83(5), 1543-1559.

Portes, Alejandro, and Rubén G. Rumbaut (2006). Immigrant America: A Portrait. University of California Press.

Portes, Alejandro, and Min Zhou (1993). The New Second Generation: Segmented assimilation and its variants. Annals of the American Academy of Political and Social Science, 530(1), 74-96. 
Prokic-Breuer, Tijana, and Patricia A. McManus (2016). Immigrant Educational Mismatch in Western Europe, Apparent or Real?. European Sociological Review, 32(3), 411-438.

Raftery, Adrian E., and Michael Hout (1993). Maximally Maintained Inequality: Expansion, reform, and opportunity in Irish education, 1921-75. Sociology of Education, 41-62.

Raleigh, Elizabeth, and Grace Kao (2010). Do immigrant minority parents have more consistent college aspirations for their children? Social Science Quarterly, 91(4), 1083-1102.

Redstone Akresh, Ilana (2008). Occupational Trajectories of Legal U.S. Immigrants: Downgrading and recovery. Population and Development Review, 34(3), 435-456.

Resnick, Lauren B. (1987). Learning in School and Out. Educational Researcher, 16(9), 13-54.

Rooth, Dan O., and Jan Ekberg (2006). Occupational Mobility for Immigrants in Sweden. International Migration, 44(2), 57-77.

Salikutluk, Zerrin (2016). Why do immigrant students aim high? Explaining the aspirationachievement paradox of immigrants in Germany. European Sociological Review, 32(5), 581-592.

Saxe, Geoffrey B. (1988). Candy Selling and Math Learning. Educational Researcher, 17(6), 14-21.

Schnepf, Sylke Viola (2007). Immigrants' educational disadvantage: an examination across ten countries and three surveys. Journal of Population Economics, 20(3), 527-545.

Smith, Robert Courtney (2008). Horatio Alger lives in Brooklyn: Extrafamily support, intrafamily dynamics, and socially neutral operating identities in exceptional mobility among children of Mexican immigrants. Annals of the American Academy of Political and Social Science, 620(1), 270-290.

Statistics Sweden (2011). SCBDOK 3.2: Befolkningens utbildning (Utbildningsregistret, UREG) [Education of the Population (The Register of Education, UREG)]. UF0506, UF0537, available from: www.scb.se/Statistik/UF/UF0506/_dokument/UF0506_DO_2011.pdf

Statskontoret (2012). Organisatoriska konsekvenser av Gymnasiereformen 2011. [Organisational Implications of the Upper Secondary School Reform 2011]. Swedish Agency for Public Management. www.statskontoret.se/upload/Publikationer/2012/201223.pdf

Suárez-Orozco, Carola, and Marcelo Suárez-Orozco. (2001). Children of Immigration. Cambridge, MA: Harvard University Press. 
Sue, Stanley, and Sumie Okazaki (1990). Asian-American educational achievements: A phenomenon in search of an explanation. American Psychologist, 45(91), 3-920.

Thaning, Max, and Martin Hällsten (2018). The End of Dominance? Evaluating Measures of Family Background in Stratification Research. Working Paper no. 34, Department of Sociology, Stockholm University.

Torche, Florencia (2014). Intergenerational Mobility and Inequality: The Latin American Case. Annual Review of Sociology, 40, 619-642.

Treiman, Donald J. (1970). Industrialization and social stratification. Sociological Inquiry, 40(2), 207-234.

UNHCR [United Nations High Commissioner for Refugees] (2016). Global Trends: Forced displacement in 2015. Geneva: United Nations.

van de Werfhorst, Herman G., and Anthony F. Heath (2018). Selectivity of Migration and the Educational Disadvantages of Second-Generation Immigrants in Ten Host Societies. European Journal of Population, forthcom. doi: 10.1007/s10680-018-9484-2

Weiss, Rudolf H. (2006). Grundintelligenztest Skala 2 Revision (CFT-20R). Göttingen, Germany: Hogrefe.

World Bank (2018). World Development Report 2018: Learning to Realize Education's Promise. Washington, DC: World Bank.

Zhou, Min (1997). Segmented Assimilation: Issues, controversies, and recent research on the new second generation. International Migration Review, 31(4), 975-1008.

Zhou, Min, and Carl L. Bankston III (1994). Social Capital and the Adaptation of the Second Generation: The case of Vietnamese youth in New Orleans. International Migration Review, 28(4), 821-845.

Zhou, Min, and Susan Kim (2006). Community Forces, Social Capital, and Educational Achievement: The case of supplementary education in the Chinese and Korean immigrant communities. Harvard Educational Review, 76(1), 1-29. 
Table 1: Descriptive statistics for variables in the CILS4EU sample.

\begin{tabular}{|c|c|c|c|c|c|c|}
\hline & Obs & Mean & Std Dev & Min & Max & Wave \\
\hline Cognitive test & 1592 & 15.78 & 5.25 & 0 & 27 & 1 \\
\hline Language test & 1600 & 15.23 & 4.95 & 0 & 30 & 1 \\
\hline \multicolumn{7}{|l|}{ School behavior* } \\
\hline Come late to school & 1655 & 3.75 & 1.14 & 1 & 5 & 1 \\
\hline Argue with teacher & 1655 & 4.45 & 0.88 & 1 & 5 & 1 \\
\hline Get a punishment in school & 1649 & 4.63 & 0.71 & 1 & 5 & 1 \\
\hline Skip lesson without permission & 1646 & 4.54 & 0.85 & 1 & 5 & 1 \\
\hline \multicolumn{7}{|l|}{ Self-assessment ${ }^{\dagger}$} \\
\hline Sure I can do well at school & 1650 & 1.50 & 0.69 & 1 & 5 & 1 \\
\hline Sure I can get good grades & 1650 & 1.60 & 0.73 & 1 & 5 & 1 \\
\hline Sure I can do well at school & 1311 & 1.42 & 0.65 & 1 & 5 & 2 \\
\hline Sure I can get good grades & 1302 & 1.64 & 0.76 & 1 & 5 & 2 \\
\hline Would succeed at academic track & 1295 & 1.70 & 0.93 & 1 & 5 & 2 \\
\hline Would succeed at university & 1286 & 1.83 & 0.97 & 1 & 5 & 2 \\
\hline \multicolumn{7}{|l|}{ Perceived value } \\
\hline Education important for good life & 1646 & 1.23 & 0.53 & 1 & 5 & 1 \\
\hline Important for me to get good grades & 1654 & 1.31 & 0.59 & 1 & 5 & 1 \\
\hline University important to get good job & 1303 & 1.54 & 0.86 & 1 & 5 & 2 \\
\hline Willing to live on less to study & 1295 & 2.22 & 1.16 & 1 & 5 & 2 \\
\hline Willing move to get right education & 1296 & 2.24 & 1.19 & 1 & 5 & 2 \\
\hline Career aspiration (ISEI) & 957 & 68.87 & 18.99 & 14.21 & 88.96 & 2 \\
\hline Grade sum & 1646 & 198.97 & 65.47 & 0 & 320 & - \\
\hline Academic track & 1646 & 0.42 & 0.49 & 0 & 1 & - \\
\hline \multicolumn{7}{|l|}{ Parental education } \\
\hline Educational selectivity & 1564 & 53.65 & 27.65 & 0.04 & 99.25 & - \\
\hline Years of schooling & 1618 & 10.66 & 2.91 & 5 & 20 & - \\
\hline \multirow[t]{2}{*}{ National average years of sch. } & 1619 & 8.24 & 2.23 & 3.35 & 13.18 & - \\
\hline & Obs & Freq & Percent & & & Wave \\
\hline \multicolumn{7}{|l|}{ Ethnic origin } \\
\hline Nordic & 1672 & 54 & 3.23 & & & 1 \\
\hline Western (incl U.S.) & 1672 & 42 & 2.51 & & & 1 \\
\hline South Europe & 1672 & 315 & 18.84 & & & 1 \\
\hline East Europe & 1672 & 127 & 7.60 & & & 1 \\
\hline Middle East & 1672 & 594 & 35.53 & & & 1 \\
\hline Iran & 1672 & 67 & 4.01 & & & 1 \\
\hline Africa & 1672 & 223 & 13.34 & & & 1 \\
\hline Asia & 1672 & 140 & 8.37 & & & 1 \\
\hline Latin America & 1672 & 58 & 3.47 & & & 1 \\
\hline Missing/other & 1672 & 52 & 3.11 & & & 1 \\
\hline \multicolumn{7}{|l|}{ Immigrant generation } \\
\hline 1st generation & 1672 & 293 & 17.56 & & & 1 \\
\hline 1.5 gen (arrived before age 10 ) & 1672 & 366 & 21.93 & & & 1 \\
\hline 2nd generation & 1672 & 1010 & 60.52 & & & 1 \\
\hline \multicolumn{7}{|l|}{ Gender } \\
\hline $1=$ female & 1672 & 850 & 50.84 & & & 1 \\
\hline
\end{tabular}


Table 2: Standardized $\beta$-coefficients for immigrant parents' education (Years of schooling, Educational selectivity) and control variables from regressions of various child outcomes reported in the Swedish CILS4EU. Standard errors clustered on school classes in parentheses.

\begin{tabular}{|c|c|c|c|c|}
\hline & Cognitive test & Language test & School behavior & Grade sum \\
\hline \multicolumn{5}{|l|}{ Model 1} \\
\hline Years of schooling & $0.302(0.040) * * *$ & $0.258(0.032) * * *$ & $0.040(0.044)$ & $0.241(0.041) * * *$ \\
\hline Educational selectivity & $-0.146(0.041) * * *$ & $-0.099(0.035) * *$ & $-0.015(0.045)$ & $-0.003(0.040)$ \\
\hline $\mathrm{R}^{2}$ & 0.07 & 0.13 & 0.01 & 0.12 \\
\hline \multicolumn{5}{|l|}{ Model 2} \\
\hline Years of schooling & $0.185(0.048) * * *$ & $0.194(0.047) * * *$ & $0.070(0.057)$ & $0.237(0.058) * * *$ \\
\hline Educational selectivity & $-0.017(0.051)$ & $-0.028(0.049)$ & $-0.048(0.061)$ & $0.002(0.057)$ \\
\hline National average schooling & $0.140(0.034) * * *$ & $0.069(0.037)$ & $-0.037(0.039)$ & $0.009(0.038)$ \\
\hline $\mathrm{R}^{2}$ & 0.08 & 0.13 & 0.01 & 0.12 \\
\hline \multicolumn{5}{|l|}{ Model 3} \\
\hline Years of schooling & $0.135(0.046) * *$ & $0.158(0.047) * * *$ & $0.060(0.052)$ & $0.189(0.054) * * *$ \\
\hline Educational selectivity & $0.031(0.048)$ & $0.011(0.048)$ & $-0.030(0.054)$ & $0.046(0.052)$ \\
\hline National average schooling & $0.077(0.067)$ & $0.030(0.067)$ & $-0.083(0.063)$ & $-0.018(0.058)$ \\
\hline Region of origin & Yes & Yes & Yes & Yes \\
\hline $\mathrm{R}^{2}$ & 0.13 & 0.15 & 0.04 & 0.17 \\
\hline \multirow[t]{2}{*}{$\bar{N}$} & 1672 & 1672 & 1672 & 1672 \\
\hline & Self-assessment & Perceived value & Career aspiration & Academic track \\
\hline \multicolumn{5}{|l|}{ Model 1} \\
\hline Years of schooling & $0.054(0.041)$ & $-0.205(0.042) * * *$ & $-0.076(0.049)$ & $-0.006(0.021)$ \\
\hline Educational selectivity & $0.060(0.041)$ & $0.210(0.044) * * *$ & $0.229(0.046) * * *$ & $0.108(0.019) * * *$ \\
\hline $\mathrm{R}^{2}$ & 0.03 & 0.03 & 0.07 & 0.08 \\
\hline \multicolumn{5}{|l|}{ Model 2} \\
\hline Years of schooling & $0.096(0.060)$ & $-0.125(0.055) *$ & $-0.017(0.066)$ & $0.039(0.026)$ \\
\hline Educational selectivity & $0.014(0.063)$ & $0.124(0.058) *$ & $0.162(0.068) *$ & $0.058(0.025) *$ \\
\hline National average schooling & $-0.045(0.046)$ & $-0.080(0.041) *$ & $-0.068(0.046)$ & $-0.048(0.017) * *$ \\
\hline $\mathrm{R}^{2}$ & 0.03 & 0.03 & 0.07 & 0.08 \\
\hline \multicolumn{5}{|l|}{ Model 3} \\
\hline Years of schooling & $0.099(0.061)$ & $-0.122(0.055) *$ & $-0.008(0.065)$ & $0.033(0.025)$ \\
\hline Educational selectivity & $0.022(0.065)$ & $0.127(0.056) *$ & $0.161(0.064) *$ & $0.064(0.025) *$ \\
\hline National average schooling & $-0.131(0.087)$ & $0.019(0.078)$ & $-0.056(0.083)$ & $-0.042(0.034)$ \\
\hline Region of origin & Yes & Yes & Yes & Yes \\
\hline $\mathrm{R}^{2}$ & 0.05 & 0.07 & 0.10 & 0.10 \\
\hline $\bar{N}$ & 1672 & 1672 & 1672 & 1672 \\
\hline
\end{tabular}

Note: $* p<.05, * * p<.01, * * * p<.001$. Linear regressions estimated with full information maximum likelihood for missing data. Region of origin is a categorical variable encompassing 9 groups of countries. All models include controls for student gender and immigrant generation. For further details and definitions refer to the running text. 

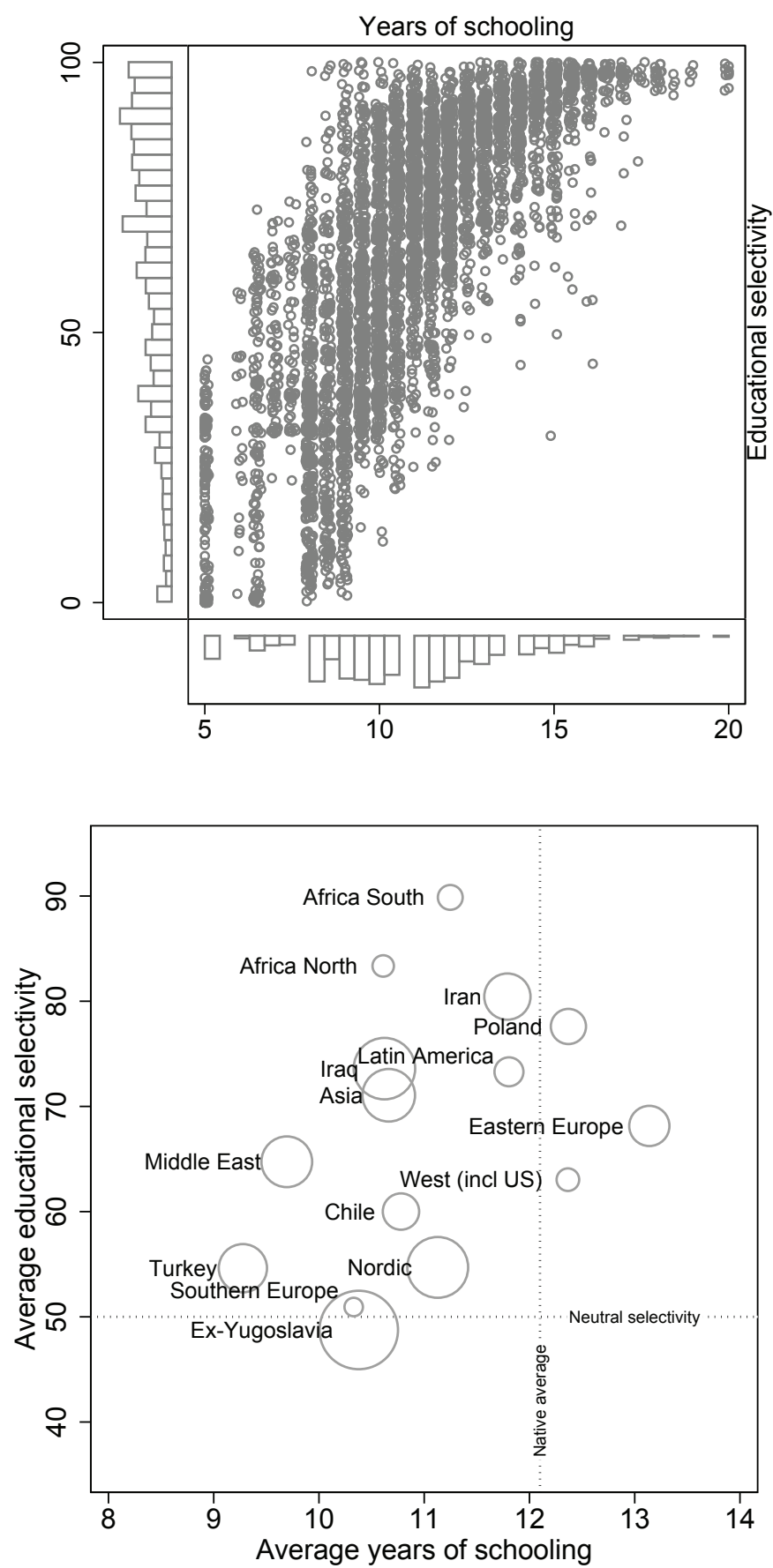

Figure 1: Top panel: scatterplot of immigrant parents' education as percentile position in country of origin (vertical axis) and years of schooling (horizontal axis), averaged over both parents. Bivariate correlation $r=0.76$. Bottom panel: group averages of immigrant parents' educational selectivity and years of schooling; circles represent the relative size of each group. Top panel $N=7,776$ (10 percent random sample); bottom panel $N=77,767$. 


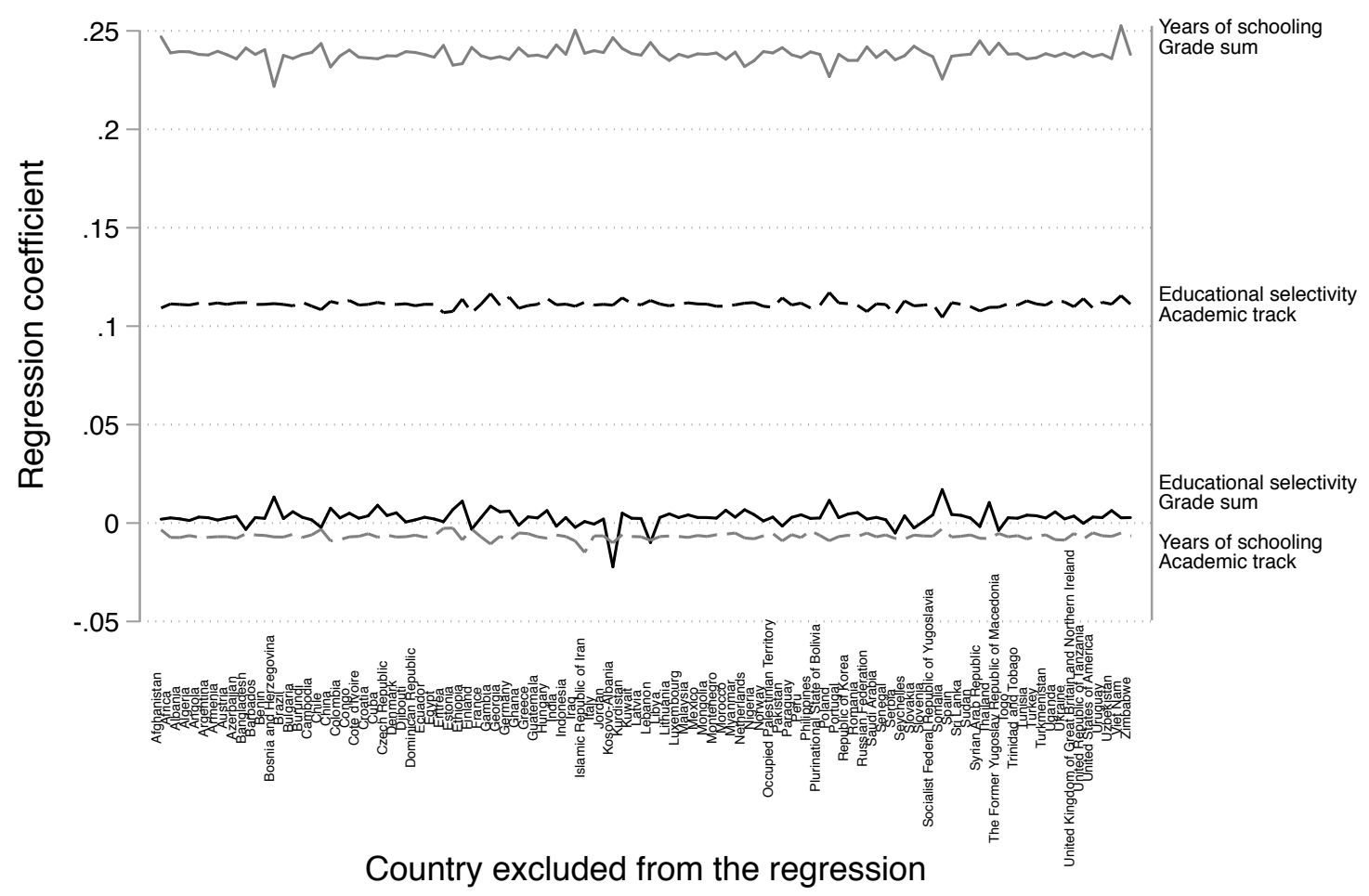

Figure 2: Robustness to the exclusion of single origin countries. The graph depicts recalculated coefficient estimates for Model 1, Table 2, for a set of regressions successively dropping all observations from a single origin country at a time. The exclusion is based on mother's country of birth, but results are similar for the father. $N=1,472-1,671$. 

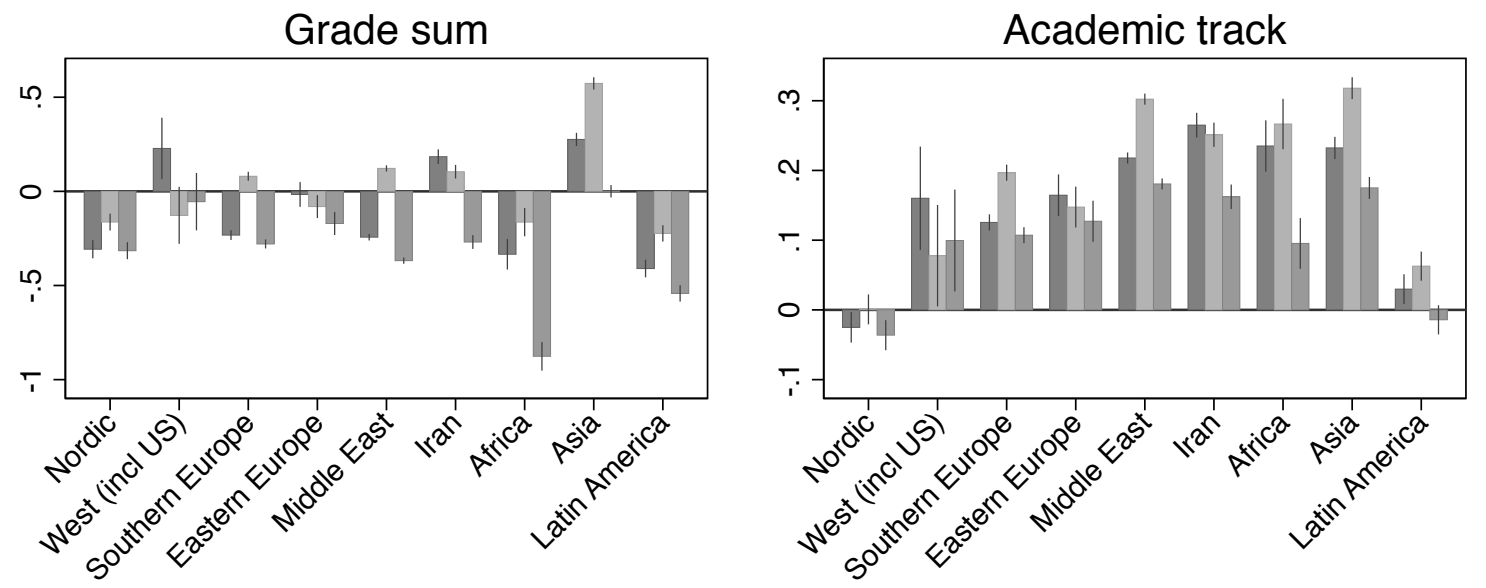

Controls: None $\quad$ Years of schooling Educational selectivity

Figure 3: Estimated group differences in educational outcomes compared to the native majority (two parents born in Sweden). Second-generation immigrants only. Left panel: final grade sum ( $z$-standardized), right panel: probability of academic track choice, net of achieved grades (linear probability model). Error bars indicate $95 \%$ confidence intervals. Models with varying controls for parental education: None, Years of schooling, Educational selectivity. 2011-2012 cohorts, $N=334,904$. 